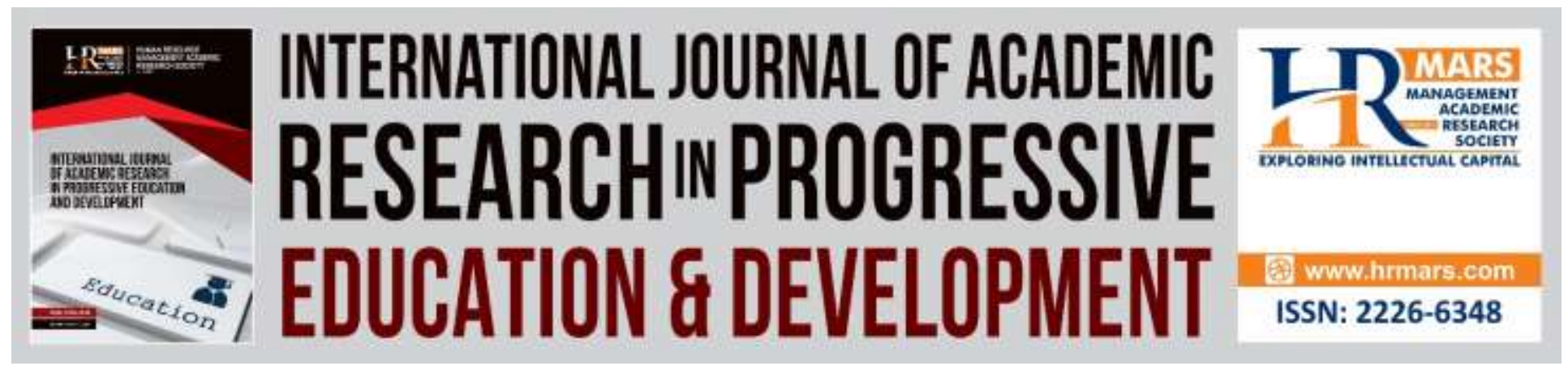

\title{
Moving toward Transdisciplinary Oriented Research-Based Learning (TRBL) Approach Using Multimedia Technologies in Higher Education
}

\author{
Nurul Aisyah Kamrozzaman, Jamaludin Badusah, Muna Ruzanna, Helmi \\ Norman
}

To Link this Article: http://dx.doi.org/10.6007/IJARPED/v8-i4/6902

DOI:10.6007/IJARPED/v8-i4/6902

Received: 24 October 2019, Revised: 28 November 2019, Accepted: 17 December 2019

Published Online: 30 December 2019

In-Text Citation: (Kamrozzaman et al., 2019)

To Cite this Article: Kamrozzaman, N. A., Badusah, J., Ruzanna, M., \& Norman, H. (2019). Moving Toward Transdisciplinary Oriented Research-Based Learning (TRBL) Approach Using Multimedia Technologies in Higher Education. International Journal of Acdemic Research in Progressive Education and Development, 8(4), 1028-1042.

Copyright: (c) 2019 The Author(s)

Published by Human Resource Management Academic Research Society (www.hrmars.com)

This article is published under the Creative Commons Attribution (CC BY 4.0) license. Anyone may reproduce, distribute, translate and create derivative works of this article (for both commercial and non-commercial purposes), subject to full attribution to the original publication and authors. The full terms of this license may be seen

at: http://creativecommons.org/licences/by/4.0/legalcode

Vol. 8(4) 2019, Pg. 1028 - 1042

http://hrmars.com/index.php/pages/detail/IJARPED

JOURNAL HOMEPAGE

Full Terms \& Conditions of access and use can be found at

http://hrmars.com/index.php/pages/detail/publication-ethics 


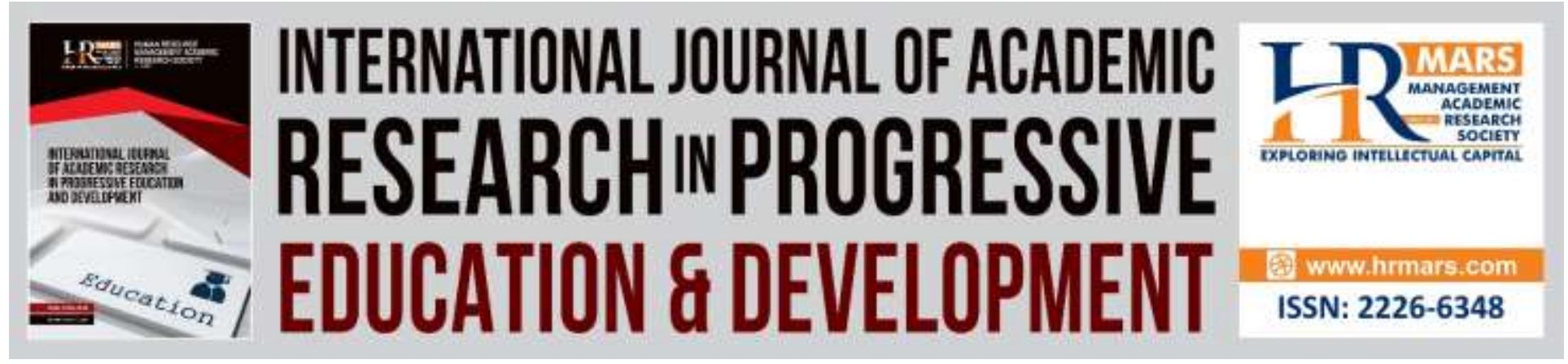

\title{
Moving toward Transdisciplinary Oriented Research-Based Learning (TRBL) Approach Using Multimedia Technologies in Higher Education
}

\author{
Nurul Aisyah Kamrozzaman, Jamaludin Badusah, Muna \\ Ruzanna, Helmi Norman \\ Faculty of Education, National University of Malaysia \\ Email: nurulaisyahkamrozzaman@gmail.com,jhb@ukm.edu.my,munaruzanna@ukm.edu.my, \\ helminorman@ukm.edu.my
}

\begin{abstract}
The rapidly changing economy requires a higher education centre to introduce new methods to facilitate graduates to compete in the job market. Job proficiency in the 21 st century is crucial in enhancing graduates' marketability. Thus, transdisciplinary is a potential field of completing the boundaries between academic and practical disciplines. Transdisciplinary learning can create new knowledge to answer and solve complex problems while simultaneously combining multiple disciplines. By applying the TRBL (Transdisciplinary Oriented Research-Based Learning) model in the teaching and research aspects of the students, it provides added value in shaping and enhancing student's soft skills as well as producing a young generation of skilled catalysts and drivers of the state.
\end{abstract}

Keywords: Transdisciplinary, Research-Based, Inquiry Learning, Multimedia, Technologies, Higher Education.

\section{Introduction}

The rapid development of Asia as a continent has created a new market direction (Jagannathan and Geronimo, 2013). It is expected that $70 \%$ of global growth over the next few years will consider talent and skills that are important in ensuring industry competitiveness (Ernst and Young, 2013; Jagannathan and Geronimo 2013). In facing the current flow of change, Asia certainly requires highly competitive workers (Jagannathan and Geronimo, 2013). As one of the thriving countries within Asia, Malaysia has the vision to become a developed nation by the year 2020. This also means that the country will need to generate high-profile and comprehensive job skills (Hanapi and Nordin, 2014; Ministry of Education Malaysia, 2014).

Meanwhile, according to the EFA Global Monitoring Report: Youth and Skills: Putting Education to Work by UNESCO (2012), there is a high need for developing job skills catered to the youth. 
The report also argued that if a country means to compete in a fast-growing world, the country must pay more attention to the development of skilled workforces which can be produced by developing graduates' job skills while they are completing their tertiary studies. Failure in the development of these occupational skills has resulted in an increased percentage of unemployed graduates who fail to secure employment (Yusoff et al. 2012).

Malaysia also faces the same scenario in which banal employment skills create difficulties for them to get jobs in both the public and private sectors (Rasul et al, 2013; Hanapi and Nordin, 2014). The 21st-century employment skills are important in enhancing graduates' marketability. Previous studies at local and global levels have found that transdisciplinary research skills and 21st-century skills are essential for graduates to compete in the job market.

When this model is integrated with support systems such as standards, assessments and curriculum, it is able to increase the involvement of students in the learning process towards excellence in today's global economy. Additionally, it has the potential to improve research skills amongst students by applying cross-disciplinary research approaches (Schneider and Rist 2013, Kagan, 2015). However, the transdisciplinary research approach is less applied in higher education. Furthermore, there is a lack of previous studies in forming a transdisciplinary approach among students. Therefore, this study explains the transdisciplinary approach using technology along with the methods of applying it to student learning.

\section{Transdisciplinary Across Fields}

Transdisciplinary research is defined as cross-disciplinary research which goes beyond the "multidisciplinary" or "interdisciplinary" approach. The method brings individuals from various disciplines together, working collaboratively towards achieving solutions from a multidisciplinary perspective. In this approach, individuals from one field go beyond their own and take into account the perspectives of other fields. This approach also encourages a problem not to be limited by just one correct answer, but rather to the possibility of various solutions to one problem or the possibility that the individual is asking for ineffective research questions (Park \& Son, 2010; Hyun, 2011; Broersma, 2014; Dremina et al., 2016).

The "multidisciplinary" and "interdisciplinary" research approaches are different from transdisciplinary research. This is because the "multidisciplinary" approach emphasizes the perspective of various fields, but these areas only affect one particular component. Meanwhile, "interdisciplinary" research applies the method of change between fields. Therefore, transdisciplinary research encompasses both "multidisciplinary" and "interdisciplinary" approaches with a broader and integrative framework (Kagan, 2015).

There are previous studies in the field of transdisciplinary research including the ones by Lang et al. 2012), Brandt et al. 2013, Schneider and Rist, 2013; Ogbiji (2018): Peprah, (2018), Patterson et al. (2014). These studies have reported the potential of a transdisciplinary research approach in which it produced collaborative research and solutions across the field (Schneider and Rist 2013; Patterson et al 2014). However, there are various issues and challenges which have been emphasized in applying transdisciplinary-nary research. Among them were the difficulties in designing the problems, selecting transdisciplinary research teams, contradictions of research methods, and the difficulty of resolving a settlement agreement for a certain issue (Lang et al. 
2010; Brandt et al. 2013). Therefore, this scenario happens to be one of the research gaps which will be bridged throughout this study.

\section{Inquiry-Based Learning}

Inquiry-based learning encourages the acquisition of new knowledge and skills through exploration and problem solving on real issues. It must be understood that there is no correct or wrong solution to the problem at hand. Recent studies that apply the Inquiry Guided Learning approach have reported that this method can foster important research skills such as critical thinking and problem solving (Lee 2012; Oxenford et al., 2012; Levy et al., 2013). One of the Inquiry-based learning approaches that have the potential to be applied in developing research skills is the cycle suggested by Levy's (2012) study. This cycle has five phases, namely (Levy 2012):

- $\quad$ Students/tutors devise questions, problems, and themes;

- $\quad$ Students utilize existing knowledge and decide the direction and method of inquiry;

- $\quad$ Students undertake an exploration of evidence and experiments using a variety of sources;

- $\quad$ Students reflect, discuss, criticize, analyze, conceptualize, synthesis, contribute, receive feedback; Students communicate and share findings from their inquiries.

Subsequently, the curriculum based on this inquiry should be implemented in one of the following four modes (Levy, 2012):

\begin{tabular}{ll} 
- & Producing \\
- & Authoring \\
- & Identifying \\
\hline
\end{tabular}

The first mode is producing; students explore open-ended questions devised by lecturers. The second mode is authoring; students explore research questions designed by them. The mode which comes after is identifying whereby students actively explore the knowledge based on the questions of the study, outlined by the lecturers. The final mode is pursuing research questions which are framed by the students to gauge the participants' response. Therefore, inquiry and transdisciplinary learning should be combined to assist in improving the skills of higher education students.

\section{A framework of TRBL (Transdisciplinary-Oriented Research-Based Learning)}

Transdisciplinary research refers to a combination of research from different disciplines or crossdisciplines which produces new concepts, theories, and methods in the production of innovation to solve community and current problems. The 21st-century Transdisciplinary-Oriented Research-Based Learning (TRBL) model covers the students' ability in the aspects of skills, knowledge, and expertise to be applied in their lives and careers.

Students should also learn basic skills in parallel with today's needs such as critical thinking, problem-solving, communication, and collaboration. When this model is integrated with support systems such as standards, assessments and curriculum, it will be able to increase the involvement of students in the learning process towards excellence in today's global economy. 


\section{INTERNATIONAL JOURNAL OF ACADEMIC RESEARCH IN PROGRESSIVE EDUCATION AND DEVELOPMENT}

Vol. 8, No. 4, 2019, E-ISSN: 2226-6348 @ 2019 HRMARS

The TRBL model was developed based on the following studies: (i) transdisciplinary-nary research (Lang et al. 2012; Schneider \& Rist 2013; Kagan 2015); (ii) 21st century skills (Partnership for 21st Century Learning 2015); (iii) learning strategy "Aalborg PBL Model" (Barge 2010); (iv) the concept of cultural research from Hanover Research (2014); (v) Education Development Plan 2015-2025 (Higher Education) (Ministry of Education 2015). This model is designed to help students in enhancing value-added skills in the future. The framework contains four main aspects interpersonal skills, research and intellectual skills, thinking skills and problem solving, and information and communication skills. Each aspect contains elements and their descriptions as shown in Figure 3.

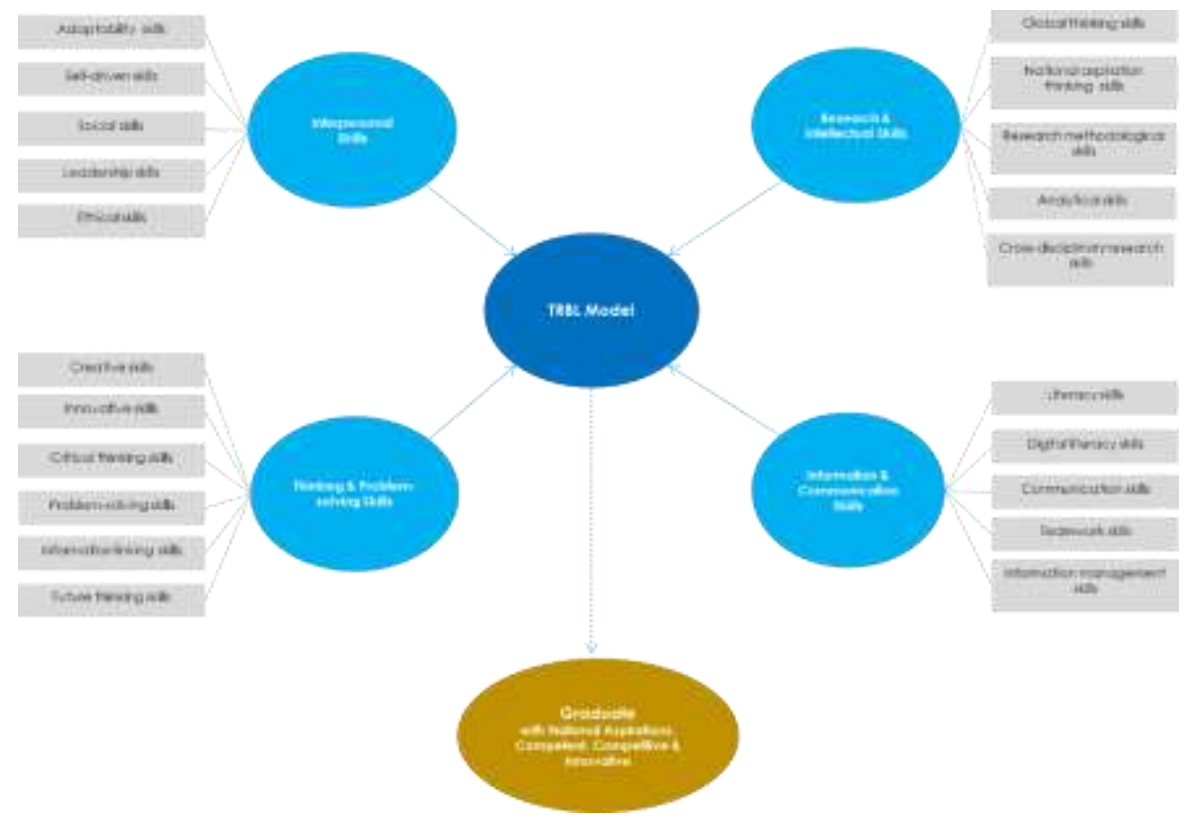

Fig 3: Transdisciplinary-Oriented Research-Based Learning (TRBL)

Table 1: Aspects and elements in the "TRBL" Model

\begin{tabular}{lll}
\hline Aspect & Element & Description \\
\hline skills & - Adaptability skill & $\begin{array}{l}\text { Customization skill is the ability to adapt } \\
\text { to various roles, schedules, and contexts. }\end{array}$ \\
\cline { 2 - 3 } & - Self-driven skill & $\begin{array}{l}\text { This skill is closely linked to the ability to } \\
\text { always demonstrate the initiative to set } \\
\text { and balance short-term and long-term } \\
\text { goals and be able to work independently } \\
\text { without supervision. }\end{array}$ \\
& $\begin{array}{l}\text { This skill is associated with the skills of } \\
\text { interacting with other individuals open- } \\
\text { mindedly and accepting various ideas }\end{array}$ \\
&
\end{tabular}


and perspectives from different fields and cultures.

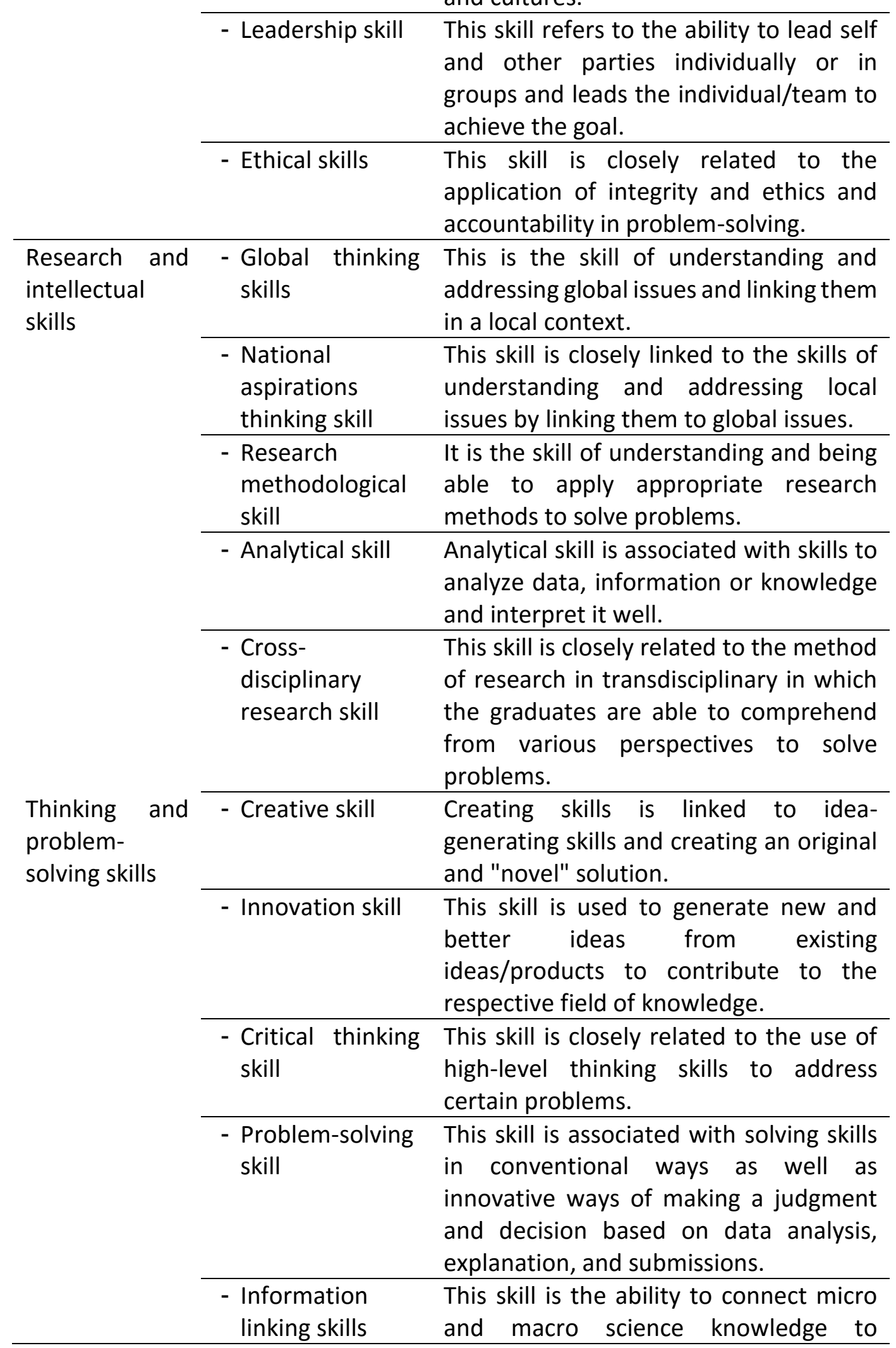


Vol. 8, No. 4, 2019, E-ISSN: 2226-6348@ 2019 HRMARS

understand a complex and holistic

problem.

\begin{tabular}{|c|c|c|}
\hline \multirow{6}{*}{$\begin{array}{l}\text { Information } \\
\text { and } \\
\text { communicatio } \\
\text { n skills }\end{array}$} & $\begin{array}{l}\text { - Future thinking } \\
\text { skill }\end{array}$ & $\begin{array}{l}\text { This skill is closely linked to the future } \\
\text { expectation skills - to relate the } \\
\text { expectation to solutions of the problem. }\end{array}$ \\
\hline & - Literacy skill & $\begin{array}{l}\text { This skill is associated with the ability of } \\
\text { literacy skills such as reading and writing. }\end{array}$ \\
\hline & $\begin{array}{l}\text { - Digital literacy } \\
\text { skill }\end{array}$ & $\begin{array}{l}\text { This skill is the ability to use digital } \\
\text { technology to solve problems. }\end{array}$ \\
\hline & $\begin{array}{l}\text { - Communication } \\
\text { skill }\end{array}$ & $\begin{array}{l}\text { This skill is closely related to the ability to } \\
\text { communicate ideas clearly and to } \\
\text { effectively communicate verbally, in } \\
\text { writing, and non-verbally. }\end{array}$ \\
\hline & - Teamwork skill & $\begin{array}{l}\text { This skill is associated with the ability to } \\
\text { collaborate with teams from various } \\
\text { fields and backgrounds and has the } \\
\text { ability to reach an agreement in solving } \\
\text { problems. }\end{array}$ \\
\hline & $\begin{array}{l}\text { - Information } \\
\text { management } \\
\text { skill }\end{array}$ & $\begin{array}{l}\text { It refers to the systematic and effective } \\
\text { management of information. }\end{array}$ \\
\hline
\end{tabular}

Strategies for Applying TRBL Approach through Courses at Higher Education Level (Case Study)

Case study on the application of TRBL strategy was conducted in the ethnic relations course at Universiti Kebangsaan Malaysia within six months from January 2019 to June 2019. Respondents of this study were students of various fields including Education, Engineering, Architecture, Science and Technology, Social Science, Economics, as well as Islamic Studies. The students were aged between 20 and 25 years old.

The learning environment used in this course is the massive open online courses (MOOC) of Ethnic Integration and Relations in Malaysia. The MOOC contains 11 modules conducted within 11 weeks. The types of learning materials provided in the MOOC are export-oriented, documentary, acting, and animated interviewed videos. The types of learning tasks used are free tasks (self-reflection) and quizzes. The MOOC is available and can be accessed via https://www.openlearning.com/courses/etnik/ page.

The teaching and learning process with the TRBL strategy has been implemented as follows. First, blended learning has been applied by conducting face-to-face and online courses using MOOC. Face-to-face lessons were held 14 times in one semester and MOOC was utilized as a learning environment that contained teaching materials. As a matter of fact, students were assigned to create a free-style video relevant to the community and has an association with 
ethnic relations to create awareness. The assignment was carried out as a group assignment in which the members of the group consisted of various ethnic backgrounds and fields.

In applying this model, ADDIE (analysis, design, development, implementation, evaluation) method has been applied. The phases are as described below.

\section{Phase 1: Analysis}

In the first phase, the task begins with the formation of transdisciplinary problems in groups with multidisciplinary learning partners. The problems are based on community concerns and accountability towards society by using scientific methods. The learning processes are as stated below.

First, MOOC is used as a platform to access learning materials and identify communityrelated issues related to ethnic relations. Due to MOOC's platform providing a learning environment which organizes massive community learning, students are able to connect with other like-minded individuals locally and abroad with different backgrounds in terms of age, knowledge, skills, and areas (Siemens, 2013).

Therefore, differences between students based on these aspects allow them to discuss with multidisciplinary students, hence, implementing transdisciplinary learning. This is in line with the 9th aspiration of the 2015-2025 Malaysia Education Development Plan (Higher Education) to promote online learning globally. For example, in the context of ethnic relations courses, MOOC helps students to better understand the community's concerns through learning materials and activities developed by lecturers and students (Ministry of Higher Education, 2015). In addition, the material includes videos containing interviews, acting scenes (Figure 2), and animation. Furthermore, MOOC provides a platform for online discussion which connects students and lecturers from any location at any time (Nordin et al. 2016).

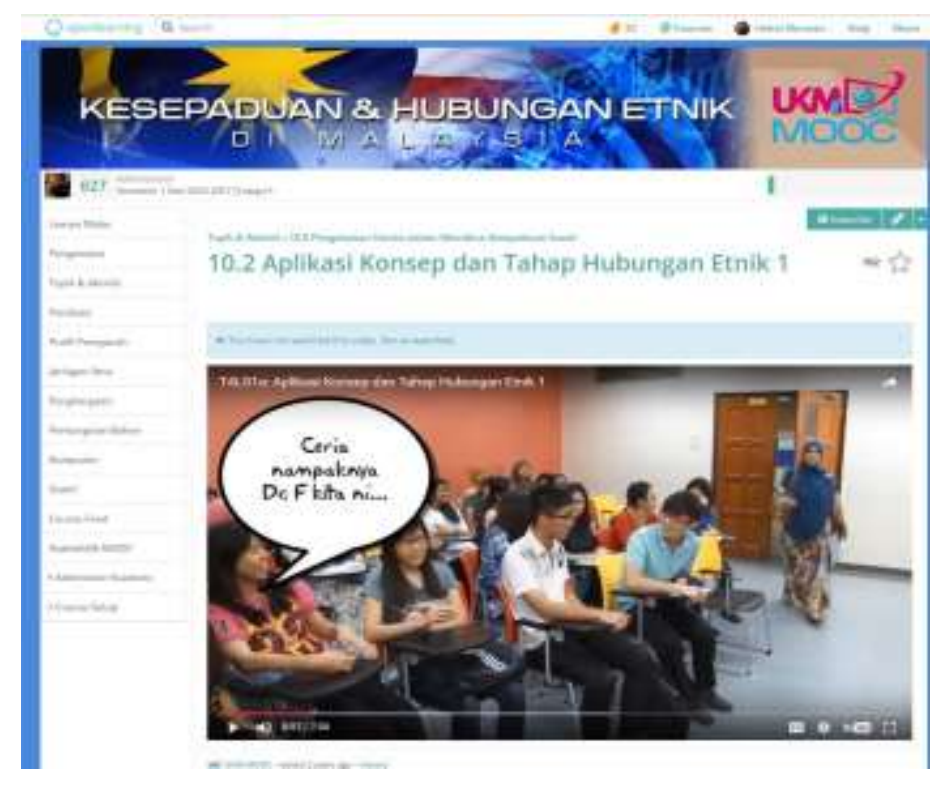


Fig. 2 Acting video in Ethnic Relations course in MOOC

As an aid, to help students better understand the problem, Kahoot is used as an interactive learning medium that has elements of learning through games. More interestingly, the medium also encourages competitive learning which has been reported to promote improvement in terms of efficacy, motivation, involvement, and academic achievement (Sung \& Hwang 2013; Hui et al. 2013).

Kahoot is a quiz that is played using a mobile device connected to the internet. The lecturer will control Kahoot from one device (mobile or computer), which is connected to the projector to display the questions to students. Next, students will answer these questions using a device (mobile or computer). Scoring is given based on the accuracy of answers and response speed. The Kahoot system will display the highest scores (first up to fifth ranks) on the main display and will also display individual scores on their respective devices. Once the game is over, the score achieved by all students will be saved and recorded online which can also be exported to Excel format.

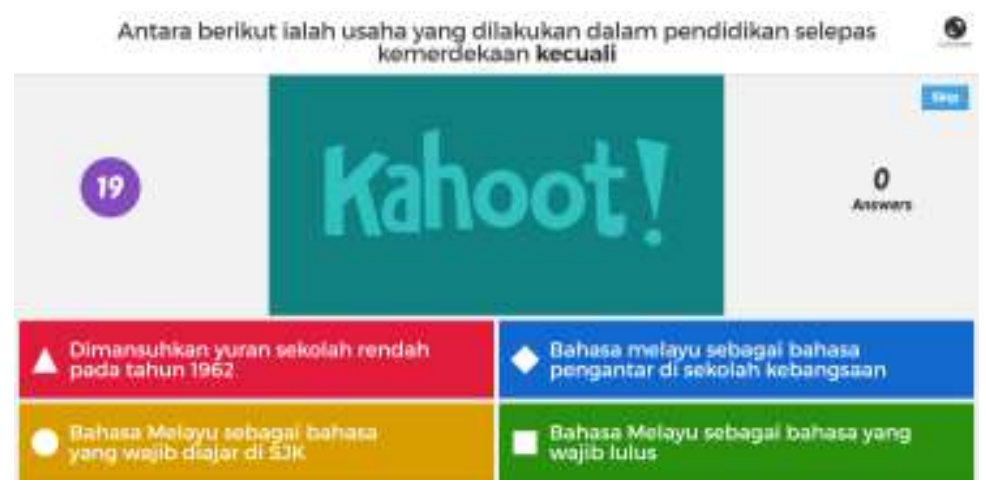

Fig. 3 Kahoot.it based learning 


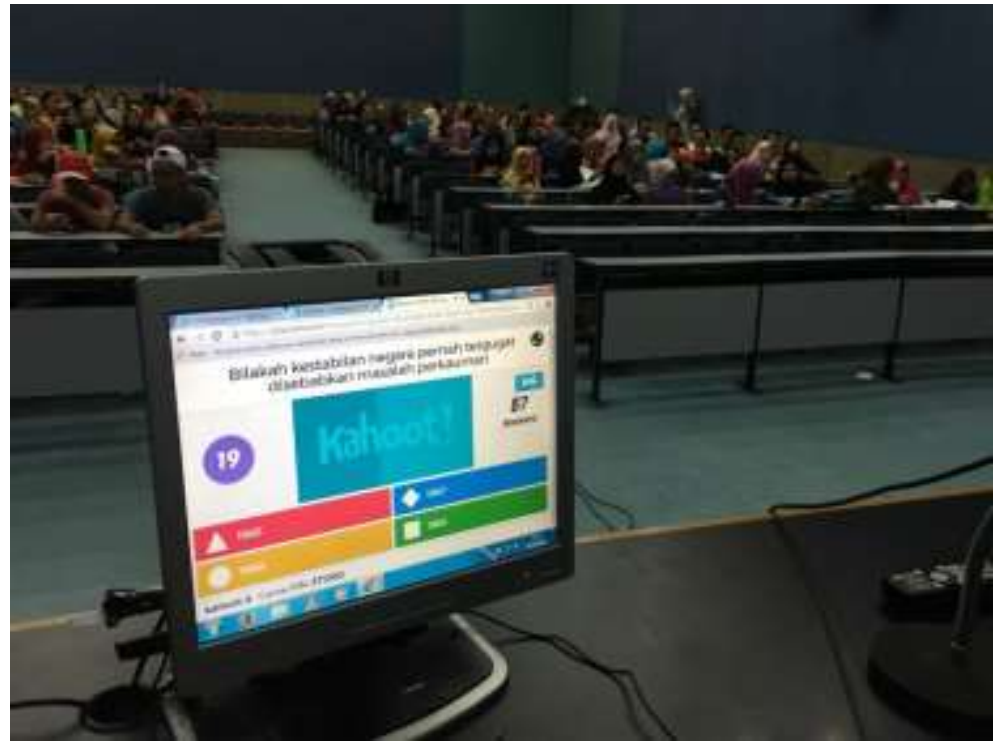

Fig 4 Classroom learning environment using Kahoot.it

The lectures delivered by ethnic relations specialists were also held to expose students with more in-depth and authentic learning on ethnic relations issues. For instance, in a teaching session, students are advised to attend a partnership session with an ethnic affiliation invited by the university (Figure 5). This approach is appropriate as it helps students to improve their understanding of community issues. In addition to sharing experiences related to ethnic relations, this approach provides students with the opportunity to raise questions and express opinions to the experts involved.

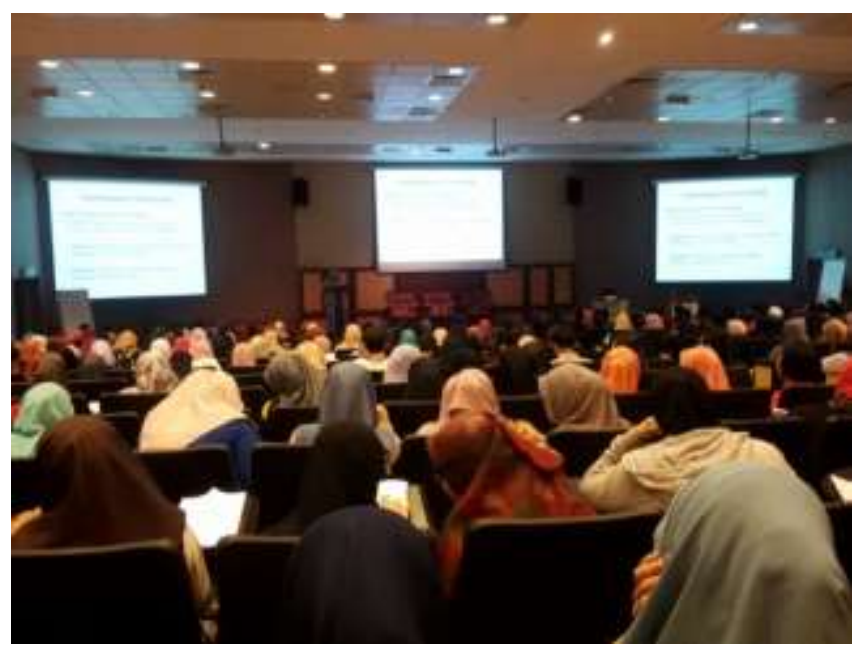

Fig. 5 Students attend a talk delivered by an invited speaker

After going through the process, the student group formed a rough sketch on the issues of society in the context of ethnic relations by placing the idea on paper. This is done through a collaborative process between multidisciplinary learning partners. The picture below is an example of a sketch. 


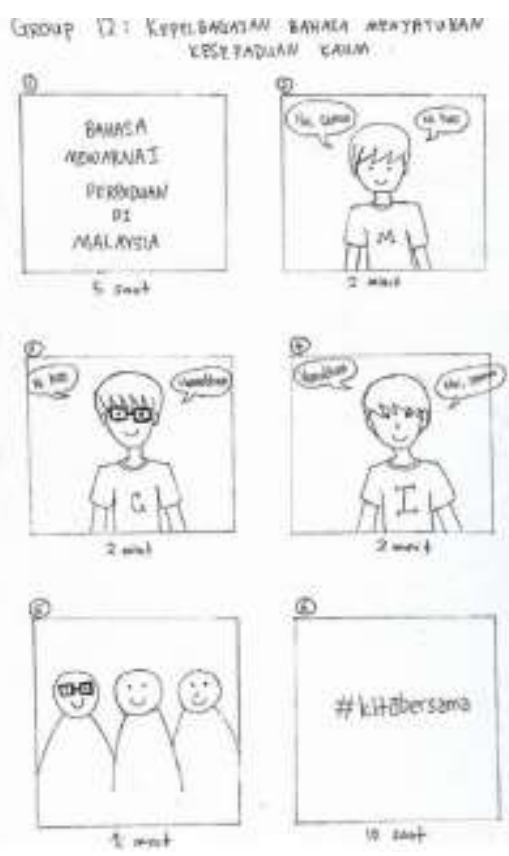

Fig. 6 An example of storyboard, generated in the analysis phase

\section{Phase 2: Design}

This phase involves designing solutions that have the potential to solve the problems identified in the previous phase. This process is done through an online brainstorming session with multidisciplinary learning partners via Coggle, an application used by student collaborators online (figure 7).

The application allows students to collaboratively design online mind maps in real-time. The purpose of using Coggle is to produce mind maps and to stimulate the process of enriching ideas to form solutions to community problems. Furthermore, students identify important aspects of the problem and the solution visually so that they can provide a consistent understanding among group members who have different perspectives. For example, the ideas and views of engineering students may be more technical while social science students may express a more conceptualized view.

Therefore, the concept of an online mind map can be a means of forming an understanding of multidisciplinary group members especially in the context of problem identification, analysis of gaps of study, identification of project approaches, project management and formation of solutions. Once an online mind map is created, it is shared among colleagues within a Facebook group site that has been created. 


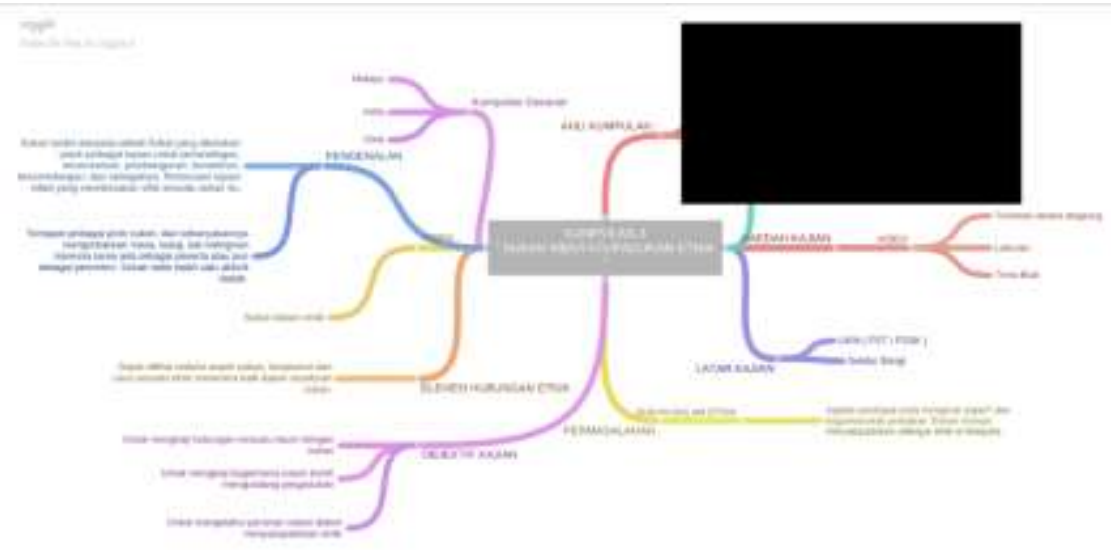

Fig. 7. Realtime Coggle discussion with multidisciplinary groups

\section{Phase 3: Development}

The third phase involves the construction and development of new transdisciplinary knowledge. The sketches and collaborative mind map designed in the previous phase were developed in the form of a video. Students are free to choose video applications that match their respective technological abilities. In developing the video, students apply context-based learning by conducting recordings independently to form new transdisciplinary knowledge solutions and potential products for the community (figure 8).

In addition, the theory of ethnic relations learned can be applied to the real context. After performing a video recording, the student edits the video using various applications like iMovie and Adobe Premiere. Edited videos will be uploaded on YouTube and Facebook Groups to facilitate multidisciplinary learning partnerships. The application of social media in learning can increase informal interaction among students and subsequently produce more open-minded students in expressing opinions.

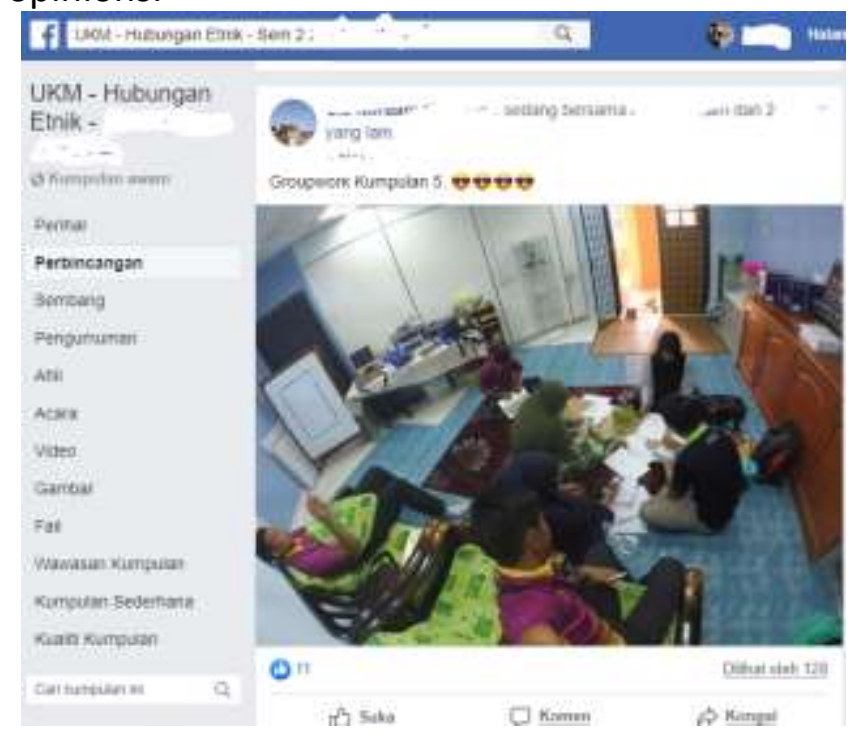

Fig. 8. A group of students uploaded a recording process related to group project topics through Facebook 


\section{Phase 4: Implementation}

This phase involves the process of sharing new interdisciplinary knowledge, developed in the development phase. The student group presents the results of the study to multidisciplinary colleagues face to face. In a face-to-face presentation, students discuss the outcome of video development to transmit new interdisciplinary knowledge to the community.

During the presentation, colleagues are given the opportunity to ask questions and give feedback on video development results. The purpose of this session is to address community issues and appropriate solutions. After receiving feedback from colleagues, improvements are made to purify and increase the quality of video results. Results after video enhancements are uploaded on MOOC for evaluation purposes.

\section{Phase 5: Assessment}

In the final phase, the evaluation process by multidisciplinary partners is carried out to evaluate whether or not the results displayed in the video can solve community problems. Students conduct peer assessment using an online questionnaire (Google Forms). In the context of lecturers, they evaluate based on two methods; analyzing student engagement at MOOC through learning analytics on $\mathrm{MOOC}$ and involvement in social media through social network analysis on Facebook.
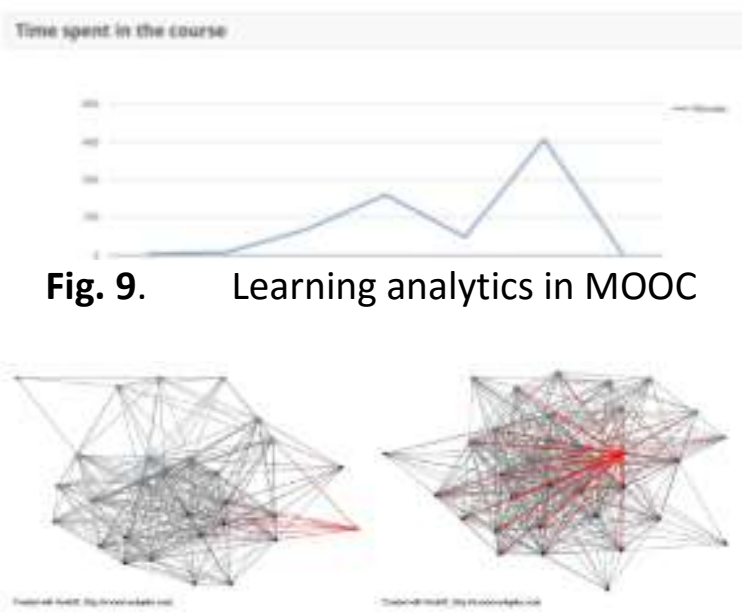

Fig. 10. Social network analysis

Once the assessment is done, a group of students makes a reflection through the production of reports, which guides students to relate new transdisciplinary knowledge. The resulting reports are made based on the formatting and assessment scores provided. In addition, this video development process provides students with an overview of the practical application of applied science to problem-solving.

\section{Implication and Conclusion}

By applying research-based transdisciplinary education through the TRBL model approach, it has implications for improving the skills of students in higher education. The model consists of four main aspects: (i) interpersonal skills, (ii) research and intellectual skills, (iii) thinking and 
problem-solving skills, and (iv) information and communication skills which have the potential to produce graduates with research skills while enhancing the marketability of graduates for the 21st-century career market. Additionally, it provides students with the opportunity to create innovation by applying environmental technology as learning material. In other words, transdisciplinary research will add value to Malaysian graduates. Therefore, it should be practised in higher education to produce future thinkers, the ones who will be able to improve the economy, education, and social of the country in parallel with other developed nations.

\section{References}

Barge, S. (2010). Principles of problem and project-based learning: The Aalborg PBL model. Aalborg University.

Bicen, H., \& Kocakoyun, S. (2018). Perceptions of Students for Gamification Approach: Kahoot as Brandt, Patric, Anna Ernst, Fabienne Gralla, Christopher Luederitz, Daniel J. Lang, Jens Newig, Florian Reinert, David J. Abson, and Henrik Von Wehrden. 2013. A review of transdisciplinary research in sustainability science. Ecological Economics, 92: 1-15.

Broersma, C. (2014). Is it Time to Change? Infusing the Transdisciplinary Approach into Social Work Studies. Journal of Sociology and Social Work, 2(2): 145-154.

Ernst \& Young. (2013). Six global trends shaping the business world: Emerging markets increase their global power. https://www.eycom.ch/en/Publications/20130129-Tracking-globaltrends/download

Hanapi, Zaliza, and Nordin, S. (2014). Unemployment among Malaysia Graduates: Graduates' Attributes, Lecturers' Competency and Quality of Education. Procedia-Social and Behavioral Sciences, 112:1056-1063.

Hanover Research. (2014). Building a culture of research: Recommended practices. Hanover: Academy Administration Practice.

Hyun, Eunsook. (2011). Transdisciplinary higher education curriculum: a complicated cultural artifact. Research in Higher Education Journal, 11(1): 1-19.

Jagannathan, Shanti, and Geronimo, D. (2013). Skills for competitiveness, jobs, and employability in developing Asia Pacific. ADB Briefs,18.

Kagan, Sacha. (2015). Artistic research and climate science: transdisciplinary learning and spaces of possibilities. Journal of Science Communication, 14(01): 1-8.

Lang, Daniel, J., Wiek, A., Bergmann, M., Stauffacher, M., Martens, P., Moll, P., Swilling, M., and Christopher, J. T. (2012). Transdisciplinary research in sustainability science: practice, principles, and challenges. Sustainability science, 7(1): 25-43.

Lee, Virginia, S. (2012). What is inquiry-guided learning? New directions for teaching and learning (129): 5-14.

Levy, Brett, L. M., Thomas, E. E., Drago, K., and Lesley, A. R. (2013). Examining studies of inquirybased learning in three fields of education: Sparking generative conversation. Journal of teacher education, 64(5): 387-408.

Levy, P. (2012). Developing inquiry-guided learning in a research university in the United Kingdom. New Directions for Teaching and Learning, 2012(129): 15-26.

Ministry of Education. (2014). Wawasan 2020. 
INTERNATIONAL JOURNAL OF ACADEMIC RESEARCH IN PROGRESSIVE EDUCATION AND

DEVELOPMENT

Vol. 8, No. 4, 2019, E-ISSN: 2226-6348 @ 2019 HRMARS

https://www.pmo.gov.my/dokumenattached/Dasar/22PERSPEKTIF_WAWASAN_2020.pd $f$.

Ministry of Education. (2015). Malaysian Education Blueprint 2015-2025 (Higher Education). Ministry of Education Malaysia: Putrajaya

Nordin, Norazah, Norman, H., and Embi, M. A. (2016). Technology acceptance of massive open online courses in Malaysia. Malaysian Journal of Distance Education 17(2): 1-16.

Oxenford, Carolyn, Summerfield, L., and Schucher, M. (2012). Marymount University: InquiryGuided Learning as a Catalyst for Change. New Directions for Teaching and Learning, 129: 71-80.

Park, Ji-Yong, and Son, J-. B. (2010). Transitioning toward transdisciplinary learning in a multidisciplinary environment. International Journal of Pedagogies and Learning, 6(1):8293.

Partnership for 21st Century Learning. (2015). Framework for 21st Century Learning.

Patterson, Ruth, E., Graham, A., Colditz, Frank, B., Hu, Kathryn, H., Schmitz, Rexford, S., Ahima, R. C. Brownson, Kenneth R. Carson et al. 2013. The 2011-2016 Transdisciplinary Research on Energetics and Cancer (TREC) initiative: rationale and design. Cancer Causes \& Control, 24(4):695-704.

Rasul, Sattar, M., Rauf, R. A. A., and Mansor, A. N. (2013). Employability Skills Indicator as Perceived by Manufacturing Employers. Asian Social Science, 9(8):42-46.

Schneider, Flurina, and Rist, S. (2014). Envisioning sustainable water futures in a transdisciplinary learning process: combining normative, explorative, and participatory scenario approaches. Sustainability Science, 9(4): 463-48.

Siemens, George. (2013). Learning analytics: The emergence of a discipline. American Behavioral Scientist, 57(10): 1380-1400.

Sung, Han-Yu, and Hwang, G. (2013). A collaborative game-based learning approach to improving students' learning performance in science courses. Computers \& Education, 63: 43-51.

UNESCO. (2012). EFA Global Monitoring Report: Youth and Skills: Putting Education to Work. UNESCO Publishing: Paris.

Yusoff, Md, Y., Omar, M. Z., Zaharim, A., Mohamed, A., and Muhamad, N. (2012). Employability Skills Performance Score for Fresh Engineering Graduates in Malaysian Industry. Asian Social Science, 8(16): 140-145.

Ogbiji, J. E. (2018). A Comparative Study of the Administrative Effectiveness of Principals of Public and Private Secondary School in Cross River State, Nigeria. International Journal of Academic Research in Progressive Education and Development, 7(4), 427-434.

Dremina, M. A., Davydova, N. N., \& Kopnov, V. A. (2016). Lifelong Learning in Russia: History, Concepts \& Practices. Multilingual Academic Journal of Education and Social Sciences, 4(2), 30-46.

Peprah, W. K. (2018). Predictive Relationships among the Elements of the Fraud Diamond Theory: The Perspective of Accountants, International Journal of Academic Research in Accounting, Finance and Management Sciences 8 (3): 141-148. 